\title{
Kajian penerapan metode praktikum secara efesien pada materi korosi di SMA YPPK st. Thomas aquino Kaimana
}

\author{
Theresia N. R. Boce ${ }^{* a}$, Emma J. Pongoh ${ }^{a}$, Rymond J. Rumampuk $^{a}$
}

a Universitas Negeri Manado, Tondano, 95618, Indonesia

\begin{tabular}{|c|c|}
\hline INFO ARTIKEL & A B STRACT \\
\hline Diterima 21 Mei 2019 & The application of practicum methods efficiently is able to help educators to achieve \\
\hline Disetujui 15 Juni 2019 & $\begin{array}{l}\text { success in the chemistry learning process. This study aims to determine student } \\
\text { learning outcomes in corrosion material through the learning process by applying the }\end{array}$ \\
\hline Key word: & practicum method. This research was conducted in the odd semester of the 2018/2019 \\
\hline $\begin{array}{l}\text { Practical methods, learning } \\
\text { outcomes, corrosion }\end{array}$ & $\begin{array}{l}\text { academic year for students of class XII Science in YPPK High School St. Thomas } \\
\text { Aquino Kaimana. The sample used in this study is all students of class XII IPA St. } \\
\text { Thomas Aquino Kaimana. The indicator used in this study is individual success, that }\end{array}$ \\
\hline Kata kunci: & is, if the student has reached the value of 75. Analysis of the data in this study used \\
\hline $\begin{array}{l}\text { Metode Praktikum, Hasil } \\
\text { Belajar, Korosi }\end{array}$ & the percentage completeness learning technique based on the results of the indicators \\
\hline & $\begin{array}{l}\text { obtained. The results showed that from the initial test of student learning outcomes } \\
\text { had not reached completeness (value 75) with the percentage of completeness of } \\
\text { learning outcomes of } 0 \% \text { and from the final test the results of student learning had } \\
\text { reached a grade (value }>75 \text { ) with a percentage of completeness of learning outcomes } \\
\text { of } 100 \% \text {. Based on the results of this study it can be concluded that the learning } \\
\text { outcomes of students in the subject matter of corrosion with the practicum method } \\
\text { were increased. }\end{array}$ \\
\hline
\end{tabular}

A BSTRAK

Penerapan metode praktikum secara efisien adalah dapat membantu para pendidik agar dapat mencapai keberhasilan dalam proses pembelajaran kimia. Penelitian ini bertujuan untuk mengetahui hasil belajar siswa pada materi korosi melalui proses pembelajaran dengan menerapan metode praktikum. Penelitian ini dilaksanakan pada semester ganjil tahun ajaran 2018/2019 pada siswa kelas XII IPA di SMA YPPK St. Thomas Aquino Kaimana. Sampel yang digunakan dalam penelitian ini yaitu seluruh siswa kelas XII IPA St. Thomas Aquino. Indikator yang digunakan dalam penelitian ini adalah keberhasilan secara individu yakni apabila siswa telah mencapai nilai 75. Analisis data dalam penelitian ini digunakan teknik persentase ketuntasan belajar berdasarkan nilai hasil indikator yang diperoleh. Hasil penelitian menunjukan bahwa dari tes awal hasil belajar siswa belum mencapai ketuntasan (nilai 75) dengan persentase ketuntasanan hasil belajar sebesar $0 \%$ dan dari tes akhir hasil belajar siswa telah mencapai kentusan (nilai > 75) dengan persentase ketuntasan hasil belajar sebesar $100 \%$. Berdasarkan hasil penelitian ini dapat disimpulkan bahwa hasil belajar

${ }^{*} e$-mail:

bocetheresia14@gmail.com

\section{Pendahuluan}

Ilmu kimia termasuk dalam rumpun Ilmu Pengetahuan Alam (IPA) di Sekolah Menegah Atas (SMA) yang sangat penting untuk dipelajari karena kimia dapat menggambarkan serta menjelaskan proses perubahan materi, struktur materi, dan perubahan sifat-sifatnya yang terjadi dalam kehidupan sehari-hari [1]. Oleh karena itu, dengan mempelajari kimia siswa berkesempatan untuk mengalami proses 
pembelajaran secara utuh dan memahami pengetahuan melalui metode ilmiah sehingga untuk mengetahui proses perubahan kimia yang terjadi pada kehidupan sehari-hari. Hal ini sejalan dengan tujuan mata pelajaran kimia di SMA, yakni: memperoleh pengalaman dalam menerapkan metode ilmiah melalui percobaan dan eksperimen dimana peserta didik melakukan pengujian hipotesis dalam merancang percobaan melalui pemasangan instrumen, pengambilan, pengolahan, dan penafsiran data serta menyampaikan hasil percobaan secara lisan maupun tulisan. Karena itu, laboratorium juga mempunyai peranan yang penting dalam melengkapi pembelajaran kimia.

Hasil belajar dalam dunia pendidikan sangat diperlukan karena hasil belajar merupakan faktor yang sangat penting sebagai alat untuk mengukur sejauh mana siswa dapat menguasai materi yang diajarkan oleh guru. Oleh karena itu, untuk tercapainya hasil belajar yang baik diperlukan strategi belajar yang tepat sehingga siswa menjadi lebih aktif dan memperoleh hasil yang meningkat dalam proses pembelajaran.

Permasalahan yang sangat umum bagi kurang minat para siswa dalam mengikuti proses belajar mengajar. Khususnya mata pelajaran kimia karena pembelajaran hanya menggunakan ceramah atau pembelajaran yang monoton. Sehingga para siswa kurang terampil dalam menemukan pengetahuan atau informasi sendiri. Sebagian besar para siswa dalam mengikuti proses pembelajaran kurang peran aktif sehingga sulit menangkap materi pelajaran. Mempelajari kimia tidak hanya dengan pemberian fakta dan konsep saja, tetapi peserta didik perlu dilatih untuk menemukan fakta dan konsep tersebut.

Berdasarkan hasil observasi di SMA YPPK St. Thomas Aquino Kaimana terdapat beberapa masalah dalam pembelajaran kimia, yakni guru sering menggunakan metode pembelajaran konvensional, yaitu metode ceramah dimana peserta didik lebih banyak mendengarkan penjelasan guru sehingga peserta didik kurang aktif dalam pembelajaran. Untuk menciptakan pembelajaran yang efektif dan mencapai tujuan pembelajaran yang ingin dicapai harus ditunjang dengan metode yang efektif agar dapat mencapai tujuan pembelajaran.

Pada hakekatnya, materi yang disajikan dalam pembelajaran kimia dengan konsep yang kompleks dan sebagian abstrak, sehingga diperlukan pemahaman yang benar terhadap konsep dasar yang membangun konsep tersebut. Banyak konsep kimia yang harus diserap dan dipahami oleh peserta didik dalam waktu relatif singkat sehingga peserta didik banyak yang beranggapan bahwa kimia sebagai pelajaran yang sukar, akibatnya banyak para siswa yang kurang berhasil dalam belajar kimia.

Seringkali praktikum tidak diadakan di sekolah, karena waktu yang tidak memadai, tidak tersedianya penunjang praktikum berupah panduan sedangkan jenis praktikum yang hendak dilakukan terbilang cukup sulit baik dari bahan-bahan dan alat-alat yang akan dipergunakan dalam melakukan praktikum di laboratorium tingkat SMA [2].

Metode praktikum sangat dibutuhkan dalam penyajian pelajaran dimana dalam proses belajar mengajar dengan metode praktikum ini peserta didik diberi kesempatan untuk mengalami sendiri atau melakukan sendiri, mengikuti suatu proses, mengamati suatu objek, menganalisis, membuktikan dan menarik kesimpulan sendiri mengenai suatu objek, keadaan atau proses sesuatu. Setelah peserta didik mempelajari serta membuktikan sendiri suatu kebenaran peserta didik akan tahu fakta yang sebenarnya. Tujuan dalam penelitian ini untuk mengetahui hasil belajar siswa SMA YPPK St. Thomas Aquino Kaimana pada materi korosi melalui proses pembelajaran yang menerapkan metode praktikum.

\section{Metode}

Metode yang digunakan dalam penelitian ini adalah penelitian pre-exsperimental. Desain penelitian yang digunakan dalam penelitian ini ialah One-group pre-test-post-test desing yang terlihat pada tabel 1 .

Tabel 1. One-group pretest-postest design

\begin{tabular}{lll} 
& \multicolumn{1}{c}{$\mathrm{O}_{1} \quad \mathrm{X}$} & $\mathrm{O}_{2}$ \\
Keterangan: & \\
$\mathrm{O}_{1}$ & $=$ Pre test \\
$\mathrm{X}$ & $=$ Treatmean atau Perlakuan \\
$\mathrm{O}_{2}$ & $=$ Post test
\end{tabular}


Penelitian ini dilaksanakan di SMA YPPK St. Thomas Aquino Kaimana. Penelitian ini dillaksanakan pada bulan juli dengan subjek penelitian adalah peserta didik kelas XII IPA dengan jumlah siswa 17 orang pada semester ganjil tahun ajaran 2018/2019.

Dalam penelitian ini untuk mendapat ketuntasan belajar yang diperoleh peserta didik. Ketuntasan belajar secara individual didapat dari KKM untuk pembelajaran kimia pada materi korosi di sekolah, Peserta didik dinyatakan tuntas jika telah mendapatkan nilai sekurang-kurangnya 75 dan di bawah 75 dinyatakan belum tuntas, sedangkan ketuntasan belajar klasikal yaitu mengukur tingkat ketuntasan belajar siswa menyeluruh. Untuk menentukan hasil belajar siswa pada pokok bahasan korosi dilakukan analisis dengan menghitung persentasi ketuntasan belajar siswa berdasarkan rumus:

$$
\% \text { Ketuntasan }=\mathrm{TB} / \mathrm{n} \times 100 \%
$$

Keterangan:

TB : Jumlah Siswa Yang Tuntas Belajar

n : Jumlah Keseluruhan Siswa kelas XI IPA

\section{Hasil dan Pembahasan Hasil Observasi}

Hasil observasi diperoleh melalui lembaran observasi dengan menggunakan komponen dan aspek pengamatan, yaitu persiapan pembelajaran yang dilakukan oleh peneliti, proses pembelajaran dan kegiatan pembelajaran oleh peserta didik yang diamati oleh guru mata pelajaran kimia sebagai pengamat. Tujuannya agar peneliti dapat mengetahui apakah metode yang diterapkan oleh peneliti dalam proses pembelajaran kimia pada materi korosi dapat mencapai tingkat keberhasilan yang tinggi ataupun lebih tinggi. Presentasi kriteria dapat dilihat pada tabel 2.

\section{Hasil Belajar Pada Materi Korosi Data pretest}

Pre-test (tes awal) dilakukan oleh peneliti untuk mengetahui kemampuan awal peserta didik dan kesuliatan peserta didik pada materi korosi di SMA YPPK St. Thomas Aquino Kaimana. Berdasarkan hasil yang diperoleh bahwa dari pre-test yang diberikan tidak ada peserta didik yang memperoleh hasil yang lebih baik. Data nilai yang diperoleh nilai tertinggi 60, dan nilai terendah 30 jadi dari ke-17 siswa belum mencapai kriteria ketuntasan dalam pembelajaran kimia pada materi korosi dikarenakan nilai-nilai yang diperoleh peserta didik tidak mencapai 75 atau mencapai nilai KKM. Adapun standar KKM dari SMA YPPK St. Thomas Aquino yang harus dicapai siswa adalah 75 .

Tabel 2. Presentasi Kriteria Pada setiap Komponen Dan Aspek Pembelajaran

\begin{tabular}{cc}
\hline Kriteria & $\%$ \\
\cline { 2 - 2 } & $\begin{array}{c}\text { Pertemuan (pembelajaran } \\
\text { dengan metode praktikum ) }\end{array}$ \\
\hline Baik & 86,9 \\
\hline Kurang & 13,4 \\
\hline
\end{tabular}

Tabel 3. Hasil Belajar Siswa Sebelum Praktikum dan Sesudah Praktikum

\begin{tabular}{|c|c|c|c|}
\hline No & $\begin{array}{l}\text { Nama } \\
\text { Siswa }\end{array}$ & $\begin{array}{c}\text { Tes Awal } \\
\text { (Sebelum } \\
\text { Praktikum) }\end{array}$ & $\begin{array}{c}\text { Tes Akhir } \\
\text { (Sesudah } \\
\text { Praktikum) }\end{array}$ \\
\hline 1 & AS & 50 & 100 \\
\hline 2 & CFM & 30 & 100 \\
\hline 3 & DK & 30 & 90 \\
\hline 4 & DAW & 50 & 100 \\
\hline 5 & EST & 30 & 90 \\
\hline 6 & EYA & 50 & 80 \\
\hline 7 & $\mathrm{JM}$ & 40 & 80 \\
\hline 8 & MYH & 50 & 100 \\
\hline 9 & MW & 30 & 80 \\
\hline 10 & LIB & 60 & 100 \\
\hline 11 & RRH & 50 & 90 \\
\hline 12 & RAT & 30 & 100 \\
\hline 13 & $\mathrm{RH}$ & 50 & 90 \\
\hline 14 & SII & 40 & 100 \\
\hline 15 & ST & 30 & 100 \\
\hline 16 & SMK & 50 & 90 \\
\hline 17 & $\mathrm{YD}$ & 30 & 80 \\
\hline \multicolumn{2}{|c|}{$\%$ Ketuntasan } & 0 & 100 \\
\hline
\end{tabular}

\section{Data posttest}

Setelah dilaksanakan pembelajaran dengan menggunakan metode praktikum kemudian dilakukan posttest peserta didik maka diperoleh nilai tertinggi 100 dan terendah 80, sesuai dengan KKM dari SMA YPPK St. Thomas Aquino Kaimana yang harus dicapai oleh siswa adalah nilai 75 yang ditentukan dari sekolah maka para siswa telah mencapai 
ketuntasan hasil belajar. Hasil belajar siswa pada materi korosi dapat dilihat pada tabel 3.

\section{Pembahasan}

Tujuan dari penelitian ini dilakukan adalah untuk mengetahui apakah penerapan metode praktikum dapat mencapai ketuntasan hasil belajar siswa pada materi korosi di kelas XII IPA di SMA YPPK St. Thomas Aquino Kaimana. Subjek yang digunakan dalam penelitian ini adalah seluruh siswa kelas XII IPA di SMA YPPK St. Thomas Aquino Kaimana dengan jumlah siswa 17 orang.

Dalam penelitian ini peneliti bertindak langsung sebagai pengajar pada materi korosi. Metode-metode yang digunakan dalam penelitian ini, antara lain: ceramah, tanya jawab, penugasan, diskusi, tes awal, praktikum dan tes akhir. Hasil belajar siswa diperoleh melalui tes akhir (sesudah praktikum) dan tes awal digunakan untuk mengetahui kemampuan siswa mengenai materi korosi sebelum diterapkan metode praktikum.

Soal yang digunakan dalam penelitan ini berjumlah 10 butir soal pilihan ganda dimana soal tes awal dan tes akhir bentuknya sama. Pada pelaksanaan tindakan dilakukan sebagai berikut:

\section{Tahap Persiapan}

Proses persiapan yang dilakukan oleh peneliti sebelum pelaksanaan penelitian, yakni:

a) Menyusun instrumen penelitian, soal dan alat evaluasi pembelajaran.

b) Menentukan waktu dan tempat penelitian

c) Peneliti kemudian melakukan observasi di tempat penelitia.

d) Menyiapkan Rencana Pelaksanaan Pembelajaran (RPP) pada materi korosi dengan menggunakan buku kimia kelas XII KTSP.

\section{Tahap Pelaksanaan}

\section{Pre-test}

Berdasarkan hasil penelitan yang diperoleh dari data tes awal atau pre-test yang diberikan sebelum diterapkan metode praktikum. Peserta didik belum mencapai kriteria ketuntasan, hal ini diperoleh dari data pretest dengan nilai tertinggi 60 , dan nilai terendah 30 jadi dari ke-17 siswa belum mencapai kriteria ketuntasan dalam pembelajaran kimia pada materi korosi dikarenakan nilai-nilai yang diperoleh peserta didik tidak mencapai 75 dan persentasi ketuntasan siswa adalah sebesar $0 \%$.

Berdasarkan hasil tersebut peneliti dapat mengetahui kemampuan awal yang dimiliki para siswa bahwa mereka belum memahami dengan sepenuhnya materi korosi.

\section{Praktikum}

a) Pendahuluan

Peneliti membuka pelajaran dengan salam, memeriksa kehadiran peserta didik setelah itu peneliti menyampaikan judul dan tujuan pembelajaran serta memberikan pertanyaan kepada peserta didik.

b) Kegiatan inti

Pelaksanaan praktikum, peserta didik menyimak penjelasaan dan arahan dari peneliti, yakni: dalam pelaksanaan praktikum peserta didik harus dibagi secara perkelompok, pengaturan kelompok dalam pelaksanakan pembelajaran dengan metode praktikum, peneliti membentuk enam (6) kelompok praktikum dimana setiap peserta didik diambil secara acak, setelah itu peneliti memberikan panduan praktikum kepada peserta didik yang akan digunakan pada saat melaksanakan praktikum. Selanjutnya, pada pelaksanaan proses pembelajaran dengan menggunakan metode praktikum peserta didik diharapkan melakukan percobaan dalam masing-masing kelompoknya sesuai dengan prosedur yang telah ditentukan dalam panduan praktikum. Selama siswa bekerja atau melakukan percobaan peneliti membimbing jalan praktikum. Peneliti juga mengontrol peserta didik yang sedang melakukan praktikum.

c) Penutup

Peneliti bersama-sama dengan peserta didik menyimpulkan hasil pembelajaran tentang korosi. Setelah itu peneliti mengakhiri pertemuan dengan berpesan kepada peserta didik agar belajar di rumah dan mencari informasi dari berbagai sumber tentang materi yang telah dipelajari untuk menambah wawasan dan persiapan ujian.

\section{Post-test}

Peneliti memberikan post-test kepada peserta didik tes yang diberikan merupakan penentuan dari ketuntasan hasil belajar siswa 
menggunakan metode praktikum. Hasil dari peserta didik yang diperoleh dari post-test menunjukan bahwa peserta didik kelas XII IPA dengan jumlah siswa 17 orang telah mencapai ketuntasan. Pelaksanaan pembelajaran dengan menggunakan metode praktikum memberikan ketuntasan hasil belajar siswa dengan persentasi ketuntasan hasil belajar sebeser 100 $\%$.

Berdasarkan hasil yang diperoleh dari penelitian penerapan metode praktikum dalam mencapai ketuntasan hasil belajar siswa pada materi korosi ternyata memberikan hasil yang sangat memuaskan.

\section{Ucapan terimakasih}

Disampaikan banyak terima kasih kepada seluruh dosen di Jurusan Kimia Fakultas Matematika dan Ilmu Pengetahuan Alam Universitas Negeri Manado dan juga SMA YPPK St. Thomas Aquino Kaimana yang berperan penting dalam pelaksanaan penelitian ini.

\section{Kesimpulan}

Berdasarkan data hasil penelitian dan analisis data yang telah diuraikan, maka dapat disimpulkan bahwa kemampuan awal yang dimiliki oleh siswa sebelum diterapkan metode praktikum pada materi korosi belum memenuhi hasil yang baik, dikarenakan nilai yang diperoleh peserta didik belum mencapai kriteria ketuntasan minimal 75 dan pesentasi ketuntasan $0 \%$ dan presentasi ketuntasan yang diperoleh siswa setelah dilakukan pembelajaran pada materi korosi dengan menggunakan metode praktikum sebesar 100\% dikarenakan hasil yang diperoleh siswa lebih dari 75

\section{Daftar Pustaka}

1. Purba, M. Kimia Untuk SMA Kelas XII IPA. 2006. Erlangga : Jakarta, Indonesia. ISBN

2. Ohoiledwarin, E. V. L. Pengembangan Penuntun Praktikum Dengan Menggunakan Metode Pembelajaran Inkuiri Berbasis Bahan Di Sekitar Pada Materi Kimia Kelas X Semester 1. Skripsi, Universitas Negeri Manado, Tondano. 2014. 